\title{
Polarity gene alterations in pure invasive micropapillary carcinomas of the breast
}

\author{
Nadège Gruel ${ }^{1,2}$, Vanessa Benhamo1,2, Jaydutt Bhalshankar ${ }^{1}$, Tatiana Popova ${ }^{1}$, Paul Fréneaux ${ }^{3}$, Laurent Arnould ${ }^{4}$, \\ Odette Mariani ${ }^{3}$, Marc-Henri Stern ${ }^{1}$, Virginie Raynal ${ }^{1}$, Xavier Sastre-Garau ${ }^{3}$, Roman Rouzier ${ }^{5}$, Olivier Delattre ${ }^{1}$ \\ and Anne Vincent-Salomon ${ }^{1,3^{*}}$
}

\begin{abstract}
Introduction: Pure invasive micropapillary carcinoma (IMPC) is a special type of breast carcinoma characterised by clusters of cells presenting polarity abnormalities. The biological alterations underlying this pattern remain unknown.

Methods: Pangenomic analysis $(n=39)$, TP53 $(n=43)$ and PIK3CA $(n=41)$ sequencing in a series of IMPCs were performed. A subset of cases was also analysed with whole-exome sequencing $(n=4)$ and RNA sequencing $(n=6)$. Copy number variation profiles were compared with those of oestrogen receptors and grade-matched invasive ductal carcinomas (IDCs) of no special type.

Results: Unsupervised analysis of genomic data distinguished two IMPC subsets: one (Sawtooth/8/16) exhibited a significant increase in 16p gains (71\%), and the other (Firestorm/Amplifier) was characterised by a high frequency of $8 \mathrm{q}$ (35\%), 17q (20\% to 46\%) and 20q (23\% to 30\%) amplifications and 17p loss (74\%). TP53 mutations (10\%) were more frequently identified in the amplifier subset, and PIK3CA mutations (4\%) were detected in both subsets. Compared to IDC, IMPC exhibited specific loss of the 6q16-q22 region (45\%), which is associated with downregulation of FOXO3 and SEC63 gene expression. SEC63 and FOXO3 missense mutations were identified in one case each (2\%). Whole-exome sequencing combined with RNA sequencing of IMPC allowed us to identify somatic mutations in genes involved in polarity, DNAH9 and FMN2 (8\% and 2\%, respectively) or ciliogenesis, BBS12 and BBS9 (2\% each) or genes coding for endoplasmic reticulum protein, HSP9OB1 and SPTLC3 (2\% each) and cytoskeleton, UBR4 and PTPN21 (2\% each), regardless of the genomic subset. The intracellular biological function of the mutated genes identified by gene ontology analysis suggests a driving role in the clinicopathological characteristics of IMPC.
\end{abstract}

Conclusion: In our comprehensive molecular analysis of IMPC, we identified numerous genomic alterations without any recurrent fusion genes. Recurrent somatic mutations of genes participating in cellular polarity and shape suggest that they, together with other biological alterations (such as epigenetic modifications and stromal alterations), could contribute to the morphological pattern of IMPC. Though none of the individual abnormalities demonstrated specificity for IMPC, whether their combination in IMPC may have a cumulative effect that drives the abnormal polarity of IMPC needs to be examined further with in vitro experiments.

\section{Introduction}

Breast carcinomas encompass numerous morphologies, phenotypes and molecular alterations [1-3]. Recent comprehensive genomic studies have focused on the most common histological (that is, invasive ductal carcinoma of no special type (IDC-NST) and lobular carcinoma) or

\footnotetext{
* Correspondence: anne.salomon@curie.fr

'INSERM U830, Institut Curie, 26 rue d'Ulm, 75248 Paris Cédex 05, France ${ }^{3}$ Department of Tumor Biology, Institut Curie, 26 rue d'Ulm, 75248 Paris Cédex 05, France

Full list of author information is available at the end of the article
}

molecular (that is, luminal, triple-negative or ERBB2) groups [4-7]. In the present study, we provide a comprehensive molecular characterisation of invasive micropapillary carcinoma (IMPC), one of the special types of invasive breast carcinoma. IMPC represents less than $2 \%$ of all invasive breast cancers [2]. This entity is characterised by proliferation of carcinomatous cells organised in clusters, separated from the extracellular matrix by an empty clear space with the cellular apical surface

\section{Biomed Central}

(c) 2014 Gruel et al.; licensee BioMed Central Ltd. This is an Open Access article distributed under the terms of the Creative Commons Attribution License (http://creativecommons.org/licenses/by/4.0), which permits unrestricted use, distribution, and reproduction in any medium, provided the original work is properly cited. 
polarised towards the outside. This inverted apical pole is clearly visualised by epithelial membrane antigen (EMA) or MUC1 staining [1] and is the hallmark of this entity.

Up to $70 \%$ of patients with IMPC have peritumoural lymphovascular invasion (LVI). This LVI rate is higher than the rates usually observed in IDC-NST (20\%). Despite the aggressive phenotype, however, IMPC is associated with a prognosis similar to that of IDC-NST and with the same axillary lymph node status [8-11]. Weigelt et al. [3] showed that IMPC are part of the transcriptomic luminal spectrum of tumours, albeit that this observation was based on the analysis of only eight cases. Researchers in two previous genomic studies based on small series of 16 and 10 cases, respectively [12,13], identified specific genomic patterns of IMPC, such as $8 \mathrm{p}$ losses, $8 \mathrm{q}$ gains and $17 \mathrm{p}$ and $16 \mathrm{q}$ losses in $50 \%$ to $100 \%$ of cases. These observations were confirmed by a recent study [14]. Another study subsequently demonstrated that the majority of IMPC cases were oestrogen receptor (ER)-positive and associated with a high proliferation rate and could therefore be considered luminal B tumours [13]. Furthermore, Marchio et al. demonstrated the existence of three different genomic patterns: "simplex", with segments of duplication and deletion of entire chromosomes or chromosome arms; "sawtooth", with numerous low-level regions of gains or losses; and "firestorm", with numerous amplifications. In addition, compared to ER- and grade-matched IDC-NST, some genomic alterations were observed more predominantly in IMPC, such as amplification on chromosomes $8 p, 8 q$ and $17 \mathrm{q}$.

Despite the results of these previous molecular studies, the biological alterations leading to polarity modifications of IMPC cells associated with high rates of axillary lymph node and LVI have still to be elucidated.

The present study, based on comprehensive genomic analysis by TP53, PIK3CA, SEC63 and FOXO3 Sanger sequencing, SNP6.0 and transcriptomic analyses of a large series of IMPC and based on whole-exome and RNA sequencing of a subset of cases, identified recurrent mutations in genes enriched in cell polarity, ciliogenesis, cell shape and cytoskeleton organisation that may converge to achieve the observed phenotype but no recurrent fusion genes.

\section{Methods}

\section{Patients and tumours}

We retrospectively selected 77 cases of invasive breast cancer (50 pure IMPC and 27 IDC-NST) on the basis of the availability of both paraffin blocks and frozen specimens from the Institut Curie (45
IMPC and 27 IDC-NST) and Centre Georges François Leclerc (5 IMPC) tumour banks. The initial treatment was surgery in all selected cases. These cases were reviewed by three experienced breast pathologists (AVS, PF and LA) and classified according to the World Health Organization criteria [1]. IMPC cases were confirmed on the basis of inside-out MUC1 staining (cancer antigen 15-3 (CA 15-3), monoclonal antibody, clone DF3; AbCys, Paris, France) at the inverted apical pole [15]. IDC-NSTs were selected as being ER-positive and were grade-matched with IMPC cases.

Whole-exome sequencing was performed for four IMPC cases and their normal DNA (peritumoural), and targeted sequencing validation was performed for forty-seven IMPC cases with a MiSeq Gene \& Small Genome Sequencer (Illumina, San Diego, CA, USA). Analysis using the Affymetrix Genome-Wide Human SNP 6.0 Array (Affymetrix, Santa Clara, CA, USA) was feasible for 39 IMPC cases, and whole-transcriptome sequencing was performed for 6 IMPC cases. The types of analyses and number of cases are listed in the flowchart in Additional file 1: Figure S1. All experiments were performed in accordance with French Bioethics Law 2004-800 and the French National Institute of Cancer Ethics Charter and with the approval of the Institut Curie Institutional Review Board and the ethics committees of our institution ("Comité de Pilotage of the Groupe Sein"). The patients gave their written informed consent for us to use their tumour specimens for research. The data were analysed anonymously.

\section{Immunohistochemical analyses}

Sections $(4 \mu \mathrm{m}$ thick) were cut from formalin-fixed, paraffin-embedded tissues derived from whole tissue sections from representative blocks for each case. These sections were cut, dried, deparaffinised and rehydrated according to standard procedures. All sections were subjected to heat-induced antigen retrieval in citrate buffer $(\mathrm{pH}$ 6.1). Antibodies against ER $\alpha$ (clone 6 F11, 1:200; Novocastra, Milton Keynes, UK), ERBB2 (clone CB11, 1:1,000; Novocastra) and MUC1 (clone DF3, 1:100; Bio $\mathrm{SB}$, Goleta, CA, USA) were incubated for 1 hour at room temperature. Staining for horseradish peroxidase antimouse and antirabbit immunoglobulin G was detected with the universal VECTASTAIN Elite ABC Kit (Vector Laboratories, Burlingame, CA, USA) with diaminobenzidine (Dako A/S, Glostrup, Denmark) as chromogen. Internal and external controls were included for each antibody. The American Society of Clinical Oncologydefined cutoffs were used to determine whether cases were positive for ER $(\geq 1 \%)$ or for ERBB2 $(\geq 30 \%)$ by complete and intense membranous staining $[16,17]$. 
MUC1 protein localisation (apical or cytoplasm) was also determined.

\section{DNA and RNA extraction}

DNA extraction and preparation for microarray experiments of tumour DNA were performed by the Institut Curie Biological Resource Center. Prior to DNA isolation, a tissue section of tumour fragments was obtained and then stained with haematoxylin and eosin to evaluate tumour cellularity. All tumours analysed contained more than $70 \%$ of tumour cells on the frozen tissue section after manual microdissection of the frozen specimen. DNA was extracted from frozen tumour samples using a standard phenol/chloroform-based procedure. The quality of DNA was assessed on agarose gels. When a smear instead of a band was observed, the sample was discarded. RNA extractions were performed using a standard previously described procedure [18].

\section{Affymetrix Genome-Wide Human SNP 6.0 Array profiling and analysis of genomic alterations}

Single-nucleotide polymorphism (SNP) mapping assays were performed according to the manufacturer's protocol (Affymetrix). Briefly, $250 \mathrm{ng}$ of genomic DNA were digested with both $N s p$ and Sty restriction enzymes in independent parallel reactions (Genome-Wide Human SNP Nsp/Sty Assay Kit 6.0; Affymetrix), ligated to the adaptors and amplified by PCR using a universal primer. After purification of PCR products with SNP clean magnetic beads (Agencourt Bioscience, Beverly, MA, USA), amplicons were quantified, fragmented, labelled and hybridised to the Affymetrix Genome-Wide Human SNP 6.0 Array. Targets were prepared when $45 \mu \mathrm{g}$ of amplified DNA were available and when the targets' size was situated between 250 and 2,000 bp, and then they were hybridised according to the manufacturer's recommendations. After washing and staining, the arrays were scanned to generate .cel software files for downstream analysis. Normalisation was performed using a genotyping console (GenomeWideSNP_6.hapmap270.na31.r1.a5.ref) provided by Affymetrix (GTC3.0.1). The data discussed in the present article have been deposited in the National Center for Biotechnology Information (NCBI) Gene Expression Omnibus [GEO:GSE37035] [19]. Genomic alterations were evaluated according to the Genome Alteration Print (GAP) methodology [20]. Copy number and allelic content profiles were detected for each tumour based on the overall pattern of alterations, as previously described and validated [20]. The cutoffs for alteration events (gains, losses and amplifications) were adapted according to the inferred ploidy. For near-diploid tumours, the genomic region with inferred copy numbers $\leq 1$ or $\geq 3$ and $\geq 6$ were considered to be regions of loss, gain and amplification, respectively. For near-tetraploid tumours, the copy number cutoffs used to define regions of loss, gain and amplification were two, six and eight, respectively. The minimal regions of amplification covering at least 25 consecutive SNPs with the same copy number status were considered to be recurrent regions when the frequency of alterations was higher than $20 \%$. Tumour profiles were visualised using GAP software (institut Curie)[20]. Partek GS software version 6.5 build 6.10.1020 (Partek, St. Louis, MO, USA) was used to generate hierarchical clustering of the Affymetrix Genome-Wide Human SNP 6.0 Array genomic data in the IMPC group. Ward's method with Euclidean distance was used to generate this clustering.

\section{The Cancer Genome Atlas breast cancer cohort}

The mutational statuses of 358 breast cancers annotated as a luminal subtype (PAM50 [21]) were extracted from The Cancer Genome Atlas (TCGA) database [22]. The frequency of mutations was calculated.

\section{Quantitative RT-PCR}

cDNA was generated using a reverse transcriptase kit (High Capacity cDNA Reverse Transcription Kit, Applied Biosystems, Foster City, CA, USA) from $1 \mu \mathrm{g}$ of total RNA. Assays-on-Demand for assessing expression level of SEC63, FOXO3 as well as the control TATA-binding protein $(T B P)$ genes were obtained from Applied Biosystems. Quantitative RT-PCR was carried out in an ABI PRISM 7500 Real-Time Thermal Cycler using TaqMan Master Mix (Applied Biosystems).

\section{Classical Sanger sequencing}

Classical Sanger sequences were performed for the following genes: TP53 (exons 4 to $10 ; n=45$ cases), PIK3CA (exons 8,10 and 21; $n=39$ cases), SEC63 (exons 1 to 21; $n=43$ cases) and FOXO3 (exons 2 to $4 ; n=51$ cases). Each PCR was performed on $30 \mathrm{ng}$ of tumour DNA (TP53 and PIK3CA) or cDNA (SEC63 and FOXO3). These genes were PCR-amplified and bidirectionally sequenced using BigDye Terminator chemistry (Applied Biosystems) with an ABI PRISM 3700 DNA Analyzer. The primer sequences are available in Additional file 2: Table S6. The functional impact of change in amino acids was determined on the basis of scoring using the PolyPhen-2 tool [23].

\section{Whole-exome sequencing}

Whole-exome sequencing was performed using the SureSelect Human All Exon 50 Mb Kit (Agilent Technologies) and the $\mathrm{SOLiD}^{\mathrm{ma}}$ experimental tracking software V4 system (Applied Biosystems). Coloured space paired-end reads 
$(50 \times 35 \mathrm{bp})$ were mapped against the UCSC Genome Browser hg19 genome (NCBI build 37.1) using bfast + bwa v0.7.0a [24]. Reads with mapping quality $<20$ and reads which were marked as duplicates by Picard v1.65 were excluded from further analysis.

Putative somatic single-nucleotide variants (SNVs) were subsequently called in exome data using SAMtools mpileup (v0.1.18 (r982:295)) [25] and VarScan v2.2.11 [26]. False-positive SNVs were excluded using the following thresholds: Fisher's exact test $P<0.05$, coverage $\geq 10 \times$, Phred base quality score $\geq 20$, minimum variant allele frequency $\geq 20 \%$ and high-quality reads supporting variants allele $\geq 4$.

For prioritisation, we omitted (1) known variants from the 1000 Genomes Project and dbSNP Coriell Cell Repository ID V137 and (2) selected missense variants with functional impact scores $>0.5$ and Genomic Evolutionary Rate Profiling (GERP) scores >3.0. We used the SeattleSeq Annotation 137 server (v7.05, June 2012) [27]. A set of potentially deleterious somatic missense SNVs was validated by classical Sanger sequencing. The validated missense variants were screened in an independent series $(n=47)$ by targeted sequencing on the Illumina MiSeq platform from IntegraGen (Evry, France). The Reactome FI Cytoscape Plugin (National Institute of General Medical Sciences, US National Institutes of Health, Bethesda, MD, USA) was used to determine the observed interactions between the mutated genes identified [28]. For whole-exome and MiSeq sequencing, the average targeted bases covered at $25 \times$ were $65 \%$ and $68 \%$, respectively.

To determine the functional impact of mutations identified in exome sequencing, PolyPhen-2 (v2.2.2, March 2012) and GERP scores were assessed [23,29]. Accumulative scores were defined on the basis of different predictor tools, including MutationTaster, Condel and MutationAssessor. The thresholds for these combined scores were as follows: for PolyPhen-2, 1 = probably damaging with probable impact on protein structure and function and $0=$ benign with no impact on protein structure and function; for GERP, $<3=$ benign, 3 to $5=$ possibly damaging and $>5=$ probably damaging.

\section{RNA sequencing}

Library preparation and paired-end $(2 \times 100 \mathrm{bp})$ RNA sequencing were performed by IntegraGen using a TruSeq RNA Sample Prep Kit and a HiSeq 2000 platform (both from Illumina), respectively. On average, 130 million reads were obtained for each sample. RNA sequencing raw reads were mapped using TopHat v2.0.6 [30] and bowtie v2.0.4 against the UCSC Genome Browser hg19 genome (NCBI build 37.1). SNV and transcriptome quantitative analysis were performed using SAMtools v0.1.8 and Cufflinks v2.0.2 [31], respectively. Expression level of validated mutations was determined using RNA sequencing data. Gene fusion analyses were performed using two known tools TopHat-Fusion v2.0.4 and deFuse v0.6 (for more detail please refer to Additional file 3: Table S8) [32-34]. Fusion's validation was performed using RT-PCR (primers listed in Additional file 4: Table S9).

\section{Gene expression analysis}

The DNA microarray used in this study was the GeneChip Human Genome U133 Plus 2.0 Array (Affymetrix), containing 54,613 probe sets. Microarray data were simultaneously normalised using the GC robust multiarray average package 1.2 in the $R$ environment ( $R$ Development Core Team). In this article, expression data are used to determine correlations between the genomic status of genes localised within the chromosome $6 \mathrm{q}$ region of minimal deletion and their level of expression by comparing the $\log _{2}$ expression signal and the DNA copy number signals using Pearson's correlation test. A correlation between expression levels with respect to DNA copy number was considered significant when the $R$-value was $>0.4$ and the $P$-value was $\leq 0.05$.

\section{Results}

IMPC tumours were predominantly pT1N1 ER-positive with high rates of ERBB2 overexpression for T1 tumours The aim of this exploratory study was to decipher genomic alterations related to the specific morphology of IMPC tumours, that is, the inverted polarity of cells, organised in clusters separated from the extracellular matrix by a clear space (Figures $1 \mathrm{~A}$ and $1 \mathrm{~B}$ ). IMPC tumours have previously been identified as luminal carcinomas. The 39 IMPC tumours subsequently analysed by Affymetrix Genome-Wide Human SNP 6.0 Array were therefore compared to 27 ER-positive and grade-matched IDC-NSTs. All clinicopathological data are provided in Additional file 5: Table S1.

On the basis of the PAM50 gene list [35], the transcriptomic analysis of IMPC tumours showed that they were either luminal A (18 of 34 cases) or luminal B (16 of 34 cases) (Additional file 6: Figure S2).

The median ages of the IMPC and IDC-NST patients were 62 and 60 years, respectively, and all patients were treated and followed at the Institut Curie between 1990 and 2010. The majority of IMPC tumours were T1 (72\%), grade 2 (51\%) and ER-positive (100\%), and ERBB2 overexpression was observed in $26 \%$ of cases.

\section{IMPC tumours harboured 17q gain/amplification associated with $6 q$ deletion}

The copy number and allelic status of each altered region in the tumour genome were determined in order to 

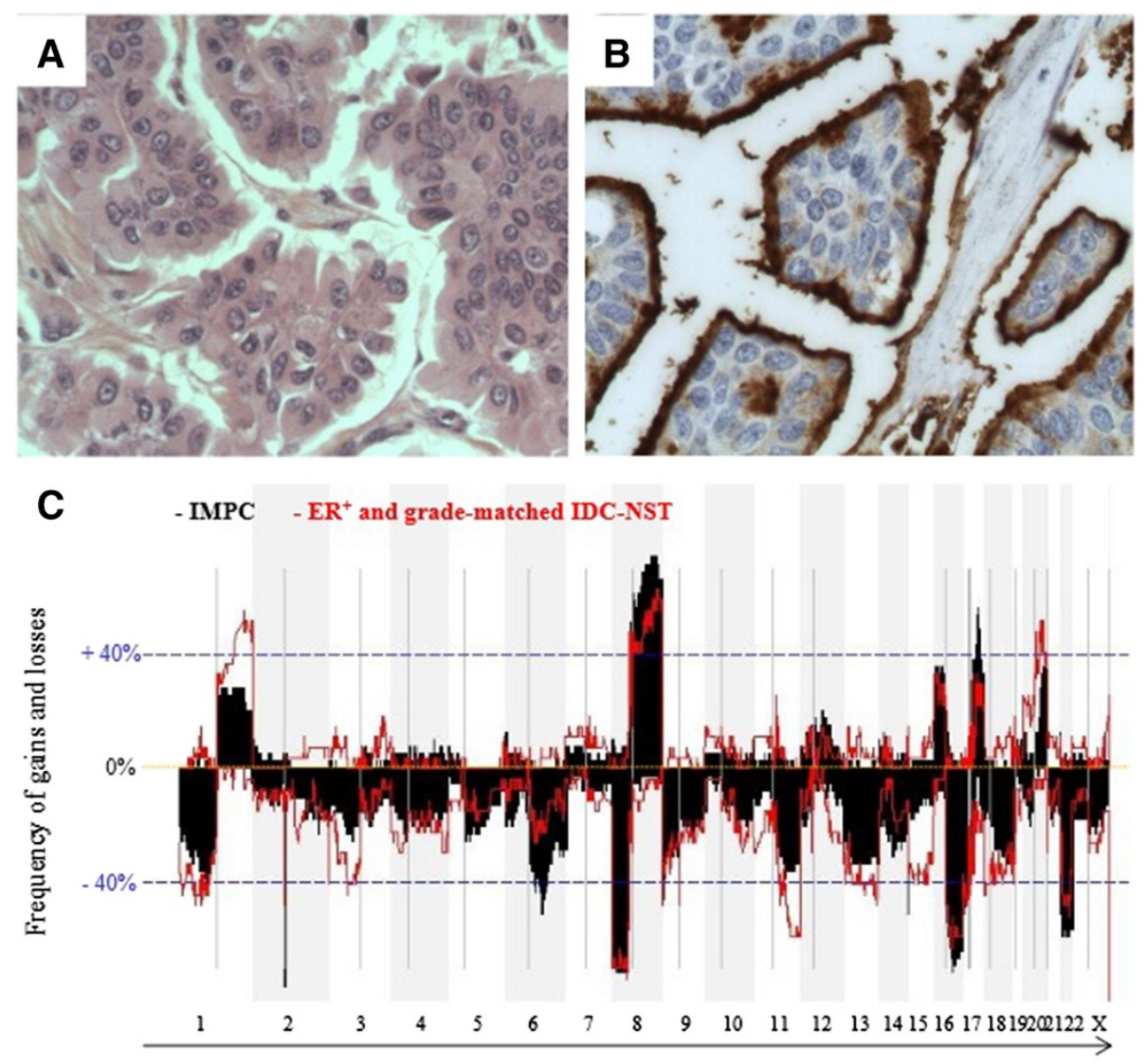

Chromosomes

Figure 1 Phenotypic and genomic characterisation of invasive micropapillary carcinoma. (A) and (B) Histological samples of an invasive micropapillary carcinoma (IMPC) of the breast composed of cell clusters surrounded by empty spaces and displaying an inside-out growth pattern, as highlighted by MUC1 staining. (C) Frequency plots of gains and losses are displayed from chromosome 1 pter on the left to chromosome Xq on the right. Alternating grey and white bands indicate chromosome boundaries. Dashed blue line represent $40 \%$ frequencies, - for losses and + for gains, respectively. ER, Oestrogen receptor; IDC-NST, Invasive ductal carcinoma of no special type.

assess chromosome number and infer the ploidy of each tumour sample. The number of breakpoints (defined as a change in copy number or allelic status within a chromosome) was evaluated for each tumour. The median numbers of breakpoints in IMPC tumours and in ER-positive and grade-matched IDC-NSTs were almost identical (65 for IMPC tumours and 79 for IDC-NSTs).

Frequencies of gains and losses are shown in Figure 1C. Recurrent amplifications (observed in more than $40 \%$ of cases) were identified on chromosomes $8 \mathrm{q}$ and $17 \mathrm{q}$, as listed in detail in Table 1 . The three most frequent regions of amplification observed in IMPCs were 8q22.1, 8q23.3-q24.23 and 17q22-q23.3, encompassing RAD54B, CCNE2 and TP53INP1 (21\% vs 5\% in IDC-NSTs), MYC (21\% vs $14 \%$ in IDC-NSTs) and BCAS3, PPM1D, TLK2, $T B X 2$ and TANC2 (22\% vs 7\%), respectively. IMPC cases also presented amplifications in the ERBB2 region (22\% vs $24 \%$ in IDC-NSTs).

As expected, some of the most frequent recurrent changes (observed in at least $40 \%$ of cases) were those commonly found in luminal B breast cancers, with gains of $8 \mathrm{q}$ being associated with losses of $8 \mathrm{p}, 16 \mathrm{q}, 17 \mathrm{p}$ and 22q [36]. However, compared to IDC-NSTs, IMPCs specifically harboured more gains of chromosome 17q22q24.3 (47\% vs 25\%) and more losses of chromosome 6q16.3-q22.31 (45\% vs 20\%) (Table 1). This chromosome $6 \mathrm{q}$ loss was associated with loss of heterozygosity (Table 1 and Figure 2B).

\section{Identification of two different genomic subsets of invasive micropapillary carcinomas}

Heterogeneous copy number profiles with a high frequency of recurrent regions of amplification and frequent combinations of recurrent alterations (such as chromosome 8p loss, 8q gain, 16q loss, 17q and/or 20q amplifications) observed in the IMPC group prompted us to search for genomic subsets. By unsupervised clustering analysis of IMPC data derived from the Affymetrix Genome-Wide Human SNP 6.0 Array, we identified two major clusters among IMPCs (Figure 2A). The first 
Table 1 Frequencies of regions of gains, losses and amplifications in invasive micropapillary carcinomas and in oestrogen receptor-positive and grade-matched invasive ductal carcinomas of no special type ${ }^{\text {a }}$

\begin{tabular}{|c|c|c|c|c|c|c|}
\hline SNP start & SNP end & Chr & Cytoband & IMPCs (\%) & IDC-NSTs (\%) & Genes of interest \\
\hline \multicolumn{7}{|c|}{ Common regions } \\
\hline \multicolumn{7}{|l|}{ Gains } \\
\hline 36948617 & 146292734 & 8 & p11.23-q24.3 & 60 & 45 & \\
\hline \multicolumn{7}{|l|}{ Losses } \\
\hline 113565 & 35436036 & 8 & p23.3-p12 & 63 & 63 & \\
\hline 46534977 & 90163275 & 16 & $\mathrm{q} 11.2-\mathrm{q} 24.3$ & $55^{\mathrm{b}}$ & 54 & \\
\hline 6689 & 18896297 & 17 & p13.3-p11.2 & 46 & $43^{b}$ & \\
\hline 16055171 & 51219006 & 22 & q11.1-q13.33 & 52 & 40 & \\
\hline \multicolumn{7}{|c|}{ Specific regions } \\
\hline \multicolumn{7}{|l|}{ Gains } \\
\hline 197811282 & 249198692 & 1 & q31.3-q44 & 23 & 48 & \\
\hline 52579874 & 67308196 & 17 & $q 22-q 24.3$ & 47 & 25 & \\
\hline 33435161 & 62648208 & 20 & q13.12-q13.33 & 17 & 44 & \\
\hline \multicolumn{7}{|l|}{ Losses } \\
\hline 101380020 & 125365648 & 6 & $q 16.3-q 22.31$ & $45^{\mathrm{b}}$ & 20 & \\
\hline 705598 & 13611533 & 18 & p11.32-p11.21 & 15 & 42 & \\
\hline 28175177 & 35313501 & 18 & $q 12.1-q 12.2$ & 24 & 40 & \\
\hline \multicolumn{7}{|l|}{ Amplifications } \\
\hline 37097563 & 38618768 & 8 & p11.23-p11.22 & 13 & 26 & FGFR1, PPAPDC1B, WHSC1L1 \\
\hline 94967717 & 97023919 & 8 & q22.1 & 21 & 5 & RAD54B, CCNE2, TP53INP1 \\
\hline 115849871 & 138121678 & 8 & q23.3-q24.23 & 21 & 14 & MYC \\
\hline 69073647 & 70229171 & 11 & $q 13.3-q 25$ & 7 & 22 & CCND1, ORAOV1, FGF19, FGF4, FGF3 \\
\hline 37298761 & 38225021 & 17 & $q 12-q 21.1$ & 22 & 24 & STARD3, ERBB2, GRB7 \\
\hline 57159990 & 62354992 & 17 & q22-q23.3 & 22 & 7 & BCAS3, TBX2, TLK2, TANC2, PPM1D \\
\hline 50695849 & 52586281 & 20 & q13.2 & 15 & 26 & ZNF217, BCAS1 \\
\hline
\end{tabular}

${ }^{a} \mathrm{Chr}$, Chromosome; IDC-NST: invasive carcinoma of no special type; IMPC, Invasive micropapillary carcinoma; SNP, Single-nucleotide polymorphism. Recurrent gains, losses or amplifications observed in more than $20 \%$ of cases after exclusion of genomic variants according to the Database of Genomic Variants (http://dgv. tcag.ca/dgv/app/home). SNP start and SNP end refer to SNP positions corresponding to the boundaries of gains, losses or amplifications. Genomic positions are provided according to human genome 19 (hg19) references in base pairs. ${ }^{\mathrm{b}}$ Existence of a homozygous deletion is observed in one case among IMPCs and IDC-NSTs studied. The lower part of the table lists the specific regions of gains, losses and amplifications that were statistically different between IMPCs and IDC-NSTs with $P<0.05$ by Fisher's exact test.

cluster was composed of 19 cases (48\%) harbouring regions of amplification located on chromosomes 8q, 17q and $20 \mathrm{q}$, with frequencies ranging from $20 \%$ to $46 \%$, hereinafter called the "Firestorm/Amplifier" subset [37]. The second cluster was composed of 16 cases (41\%) harbouring rare regions of amplification, but whole-arm copy number alterations such as $8 \mathrm{p}-/ 8 \mathrm{q}+/ 16 \mathrm{p}-/ 16 \mathrm{q}+$, hereinafter called the "Sawtooth/8/16" subset [37].

Different gains and losses distinguished "Firestorm/ Amplifier" from "Sawtooth/8/16" subsets of IMPCs (detailed in Figure 2B and Additional file 7: Table S2). Differences in genomic alterations between each of these two IMPC subsets and IDC-NSTs were then identified (presented in Additional file 8: Table S3 and Additional file 9: Table S4). In contrast to their genomic differences, the two IMPC subsets harboured identical rates of grade 3 LVI- and ER-positive cases and the same clinical stage distribution (size and $\mathrm{N}+$ number) (Additional file 10: Table S5).

\section{SEC63 and FOXO3 genes, localised in 6q minimal region} of deletion observed in both genomic groups of IMPCs, downregulation and mutation

We delineated a $1.59-\mathrm{Mb}$ minimal region of $6 \mathrm{q}$ deletion, observed in $45 \%$ of all IMPC cases. This region was observed more frequently in IMPCs than in all IDC-NSTs (Figure 2B) and luminal B IDC-NSTs (Additional file 11: Table S7 and Additional file 12: Figure S3). This deletion was further associated with a loss of heterozygosity specific to IMPCs. This region encompassed nine 

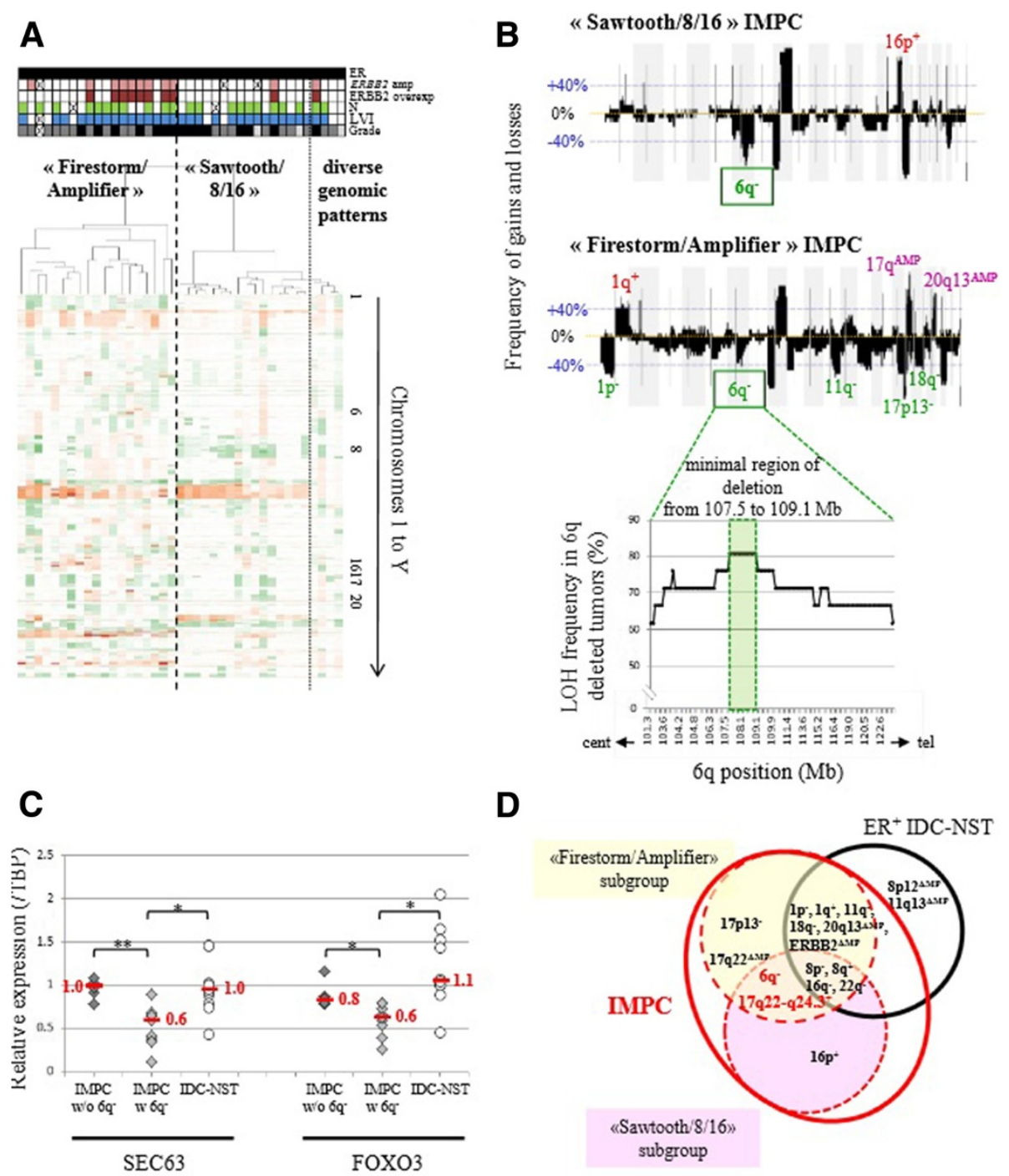

D

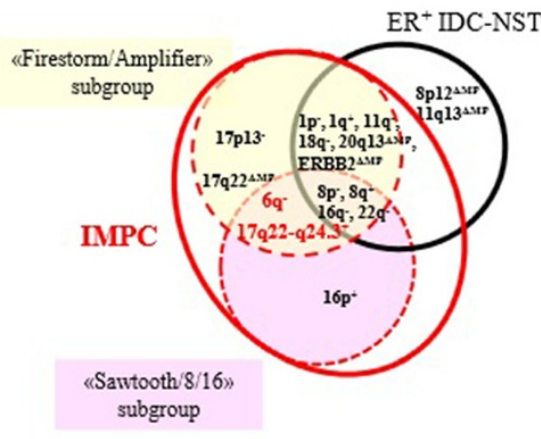

Figure 2 Identification of two invasive macropapillary carcinoma genomic subgroups. (A) Unsupervised hierarchical clustering of 39 (IMPC) tumours using Affymetrix Genome-Wide Human SNP 6.0 Array data with Partek software. Each column represents a different tumour, and each row represents single-nucleotide polymorphism (SNP) status (green for losses, red for gains and/or amplifications). Colour coding in lines above the dendrogram: black in top row = Oestrogen receptor-positive (ER+); pink = ERBB2 amplification; brown $=$ ERBB2 overexpression; green $=$ Lymph node metastasis $(\mathrm{N}+)$; blue $=$ Lymphovascular invasion-positive $(L V I+)$; pale grey $=$ grade 1 ; dark grey = grade 2; black in bottom row = grade 3. (B) Frequencies of genome copy number gains and losses plotted as a function of genome location in "Sawtooth/8/16" IMPC (upper panel) and "Firestorm/Amplifier" IMPC (middle panel). Gains and losses are displayed above or below the blue line, respectively, from chromosome 1 pter on the left to chromosome Xq on the right. Alternating grey and white bands indicate chromosome boundaries. The regions exhibiting significantly more frequent gains or losses between "Sawtooth/8/16" IMPC and "Firestorm/Amplifier" IMPC are indicated above and below the frequency plots, respectively. Frequency of loss of heterozygosity ( $\mathrm{LOH}$ ) of chromosome $6 \mathrm{q}$ assessed on the basis of Affymetrix Genome-Wide Human SNP 6.0 Array profiles observed in the tumours presenting a deletion of the chromosome 6 long arm. The minimal region of deletion is highlighted. cent, Centromere; tel, Telomere. (C) Real-time PCR results of relative expression of SEC63 and FOXO3 genes in samples of IMPC without ( $n=6$; dark-grey diamond) and with ( $n=9$; light-grey diamond) chromosome $6 \mathrm{q}$ deletion and in invasive ductal carcinoma of no special type (IDC-NST) ( $n=11$; circle) (in red: median relative value/Tata Binding Protein). w/o, without; $w$, with. ${ }^{*} P \leq 0.05,{ }^{* *} P \leq 0.001$. (D) Summary of the common and distinct genomic alterations between IMPC genomic subgroups and ER+ IDC-NSTs.

known genes according to the UCSC Genome Browser (GRCh37/hg19, February 2009). Two of the nine genes, SEC63 and FOXO3, encompassed by the common region of deletion were underexpressed in IMPC cases ( $P \leq 0.05$ by Welch test, fold change $\geq 1.5$, real-time quantitative RT-PCR) (Figure 2C) and were consequently 
sequenced. Primers used for sequencing are listed in Additional file 7: Table S6. One of the thirty-eight cases (IMPC 10; 2\% of cases) presented three FOXO3 missense mutations (Figure 3 and Table 2). One of forty- one cases, IMPC 31, presented a SEC63 missense mutation (Figure 3 and Table 2). On the basis of its PolyPhen-2 score of 1 , this mutation was considered deleterious.
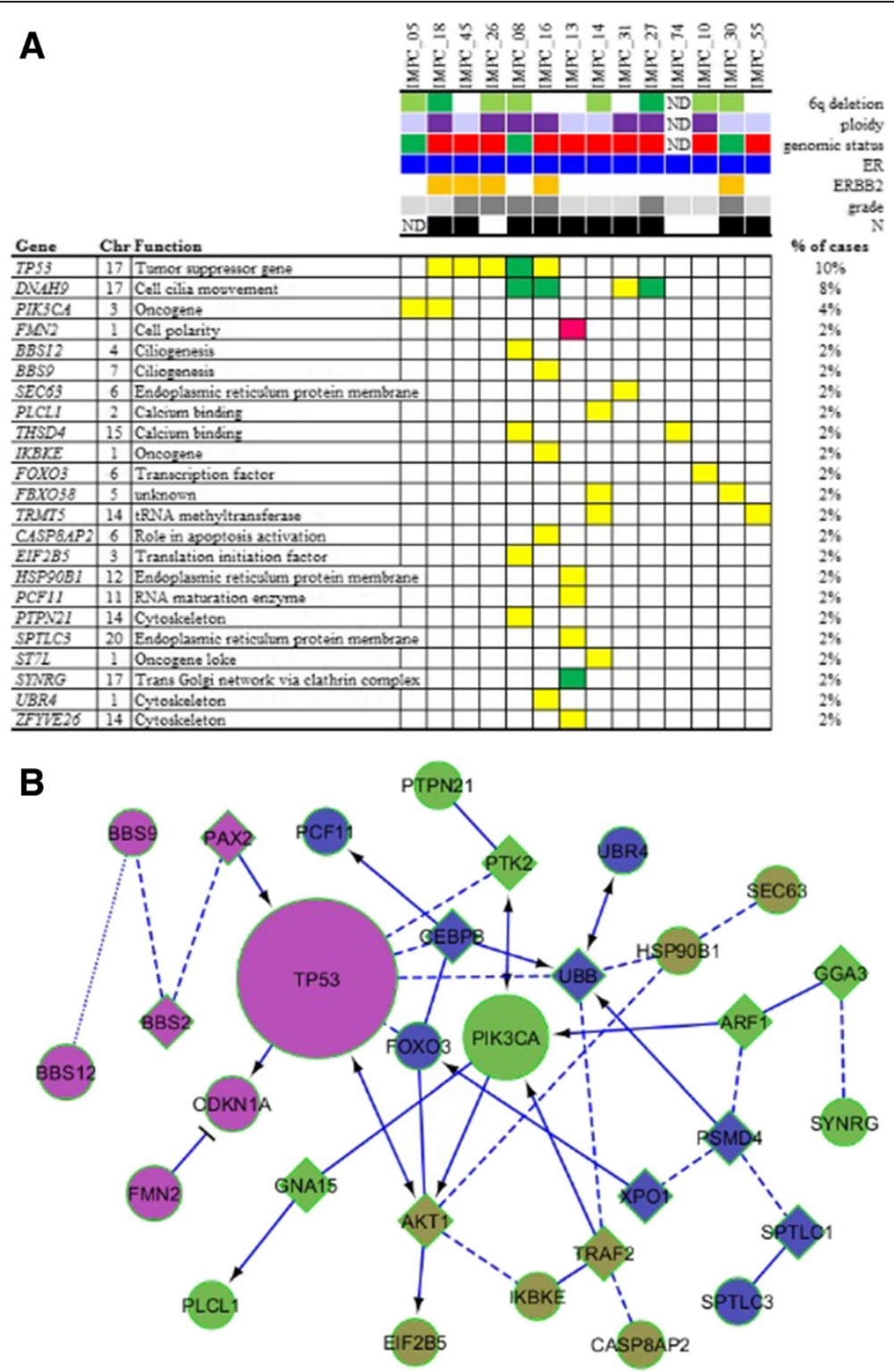

Figure 3 Mutation landscape in invasive micropapillary carcinoma according to grade, genomic subgroup and phenotype and pathway interactions between the $\mathbf{2 3}$ mutated genes. (A) Distribution of validated somatic mutations among the 50 cases as determined by whole-exome sequencing, targeted MiSeq sequencing and classical Sanger sequencing (TP53, PIK3CA, SEC63 and FOXO3). Central heatmap: distribution of significant mutations across sequenced samples with color-coding according to the allelic genomic status determined by Affymetrix Genome-Wide Human SNP 6.0 Array analysis. Yellow = neutral copy number; green = deletion, dark pink = gain. Upper chart color-coding from top to bottom: chromosome $6 \mathrm{q}$ allelic status (light green = loss of heterozygosity; dark green = deletion), tumour ploidy (dark purple = tetraploid; light purple $=$ diploid), invasive micropapillary carcinoma (IMPC) genomic group (red = "Firestorm/Amplifier"; green = "Sawtooth/8/16"), oestrogen receptor (ER) status (dark blue = positive), ERBB2 overexpression (orange = positive 3+), grade (light grey = grade 1; intermediate grey = grade 2; dark grey = grade 3), axillary lymph node status (dark = N+). Chr, chromosome; ND, Not determined. Function is defined according to the Gene Ontology database and UCSC Genome Browser. (B) Interactions and pathways between the 23 mutated genes in IMPCs deduced from the Reactome algorithm [38]. In this diagram, the functional interaction (FI) network connections are symbolised by arrows for activating/catalysing, solid lines ending in perpendicular line for inhibition, solid lines for Fls extracted from complexes or inputs, dashed lines for predicted Fls and dotted lines for defined Fls. 
Table 2 Mutations in invasive micropapillary carcinomas

\begin{tabular}{|c|c|c|c|c|c|c|c|c|c|c|c|c|}
\hline Gene & Cases, $n$ & $(\%)$ & Chr & Mutation & WH seq & MiSeq & Sanger seq & Effect of the mutation & Type of mutation & PolyPhen-2 score & GERP score & RNA-seq expression \\
\hline \multirow[t]{5}{*}{ TP53 } & 5 & (10) & 17 & GAA>CAA/p.E286Q & $x$ & NA & $x$ & Missense & Transversion & 1.00 & & Yes \\
\hline & & & & ATG>ACG/p.M246T & $x$ & NA & $x$ & Missense & Transition & 1.00 & & Yes \\
\hline & & & & GAG>AAG/p.E68K & NA & NA & $x$ & Missense & Transition & 0.09 & & ND \\
\hline & & & & TAC>TGC/p.Y234C & NA & NA & $x$ & Missense & Transition & 0.97 & & ND \\
\hline & & & & c.742_743insA & NA & NA & $x$ & Frame shift & Ins/del & & 5.91 & ND \\
\hline \multirow[t]{4}{*}{ DNAH9 } & 4 & (8) & 17 & $A>G$ & $x$ & $x$ & $x$ & Splice intron & Transition & & 4.05 & No coverage \\
\hline & & & & CGG>CAG/p.R2605Q & $x$ & $x$ & $x$ & Missense & Transition & 1.00 & & No coverage \\
\hline & & & & ATG>ATA/p.M3430I & NA & $x$ & $x$ & Missense & Transition & 0.00 & & ND \\
\hline & & & & CAG>TAG/p.Q3082* & NA & $x$ & $x$ & Nonsense & Transition & & 4.05 & ND \\
\hline \multirow[t]{2}{*}{ FBXO38 } & 2 & (4) & 5 & TAT>TGT/p.Y1058C & $x$ & $x$ & $x$ & Missense & Transition & 1.00 & & Yes \\
\hline & & & & GAA $>C A A / p . E 20 Q$ & NA & $x$ & $x$ & Missense & Transversion & 0.96 & & ND \\
\hline \multirow[t]{2}{*}{ THSD4 } & 2 & (4) & 15 & GAG>AAG/p.E476K & $x$ & $x$ & $x$ & Missense & Transition & 1.00 & & Yes \\
\hline & & & & GAG>AAG/p.E652K & NA & $x$ & $x$ & Missense & Transition & 0.96 & & ND \\
\hline \multirow[t]{2}{*}{ TRMT5 } & 2 & (4) & 14 & TTT>CTT/p.F303L & $x$ & $x$ & $x$ & Missense & Transition & 0.04 & & Yes \\
\hline & & & & GAG $>$ CAG/p.E152Q & NA & $x$ & $x$ & Missense & Transversion & 0.03 & & ND \\
\hline \multirow[t]{2}{*}{ PIK3CA } & 2 & (4) & 3 & CTC $>$ GTC/p.L540V & NA & NA & $x$ & Missense & Transversion & 0.99 & & ND \\
\hline & & & & CAG>CCG/p.Q546P & NA & NA & $x$ & Missense & Transversion & 1.00 & & ND \\
\hline \multirow[t]{3}{*}{ FOXO3 } & 1 & (2) & 6 & GCA>ACA/p.A267T & NA & NA & $x$ & Missense & Transition & 0.97 & & ND \\
\hline & & & & CCT>TCT/p.P292S & NA & NA & $x$ & Missense & Transition & 0.34 & & ND \\
\hline & & & & TTG>GTG/p.L528V & NA & NA & $x$ & Missense & Transversion & 0.03 & & ND \\
\hline BBS12 & 1 & (2) & 4 & CGC>TGC/p.R674C & $x$ & $x$ & $x$ & Missense & Transition & 1.00 & & Yes \\
\hline BBS9 & 1 & (2) & 7 & CCA>TCA/p.P77S & $x$ & $x$ & $x$ & Missense & Transition & 1.00 & & No coverage \\
\hline CASPBAP2 & 1 & (2) & 6 & GAT>AAT/p.D1420N & $x$ & $x$ & $x$ & Missense & Transition & 1.00 & & No coverage \\
\hline EIF2B5 & 1 & $(2)$ & 3 & GCA>ACA/p.A406T & $x$ & * & $x$ & Missense & Transition & 0.05 & & Yes \\
\hline FMN2 & 1 & $(2)$ & 1 & GCT >CCT/p.A659P & $x$ & * & * & Missense & Transversion & 0.74 & & No coverage \\
\hline HSP9OB1 & 1 & (2) & 12 & ACG>ATG/p.T468M & $x$ & & $x$ & Missense & Transition & 0.98 & & Yes \\
\hline IKBKE & 1 & (2) & 1 & GAC>TAC/p.D571Y & $x$ & * & $x$ & Missense & Transversion & 0.68 & & Yes \\
\hline PCF11 & 1 & (2) & 11 & AAT>AGT/p.N167S & $x$ & $x$ & $x$ & Missense & Transition & 0.02 & & Yes \\
\hline PLCL1 & 1 & (2) & 2 & AAG $>$ AAT/p.K279N & $x$ & $x$ & $x$ & Missense & Transversion & 0.98 & & No coverage \\
\hline PTPN21 & 1 & (2) & 14 & CGA>CTA/p.R864L & $x$ & $x$ & $x$ & Missense & Transversion & 1.00 & & Yes \\
\hline SEC63 & 1 & (2) & 6 & CGC>TGC/p.R217C & NA & $x$ & $x$ & Missense & Transition & 1.00 & & ND \\
\hline SPTLC3 & 1 & (2) & 20 & $\mathrm{G}>\mathrm{A}$ & $x$ & $x$ & $x$ & Splice intron & Transition & & 5.91 & No coverage \\
\hline$S T 7 L$ & 1 & $(2)$ & 1 & GAT>GCT/p.D339A & $x$ & $x$ & $x$ & Missense & Transversion & 1.00 & & Yes \\
\hline
\end{tabular}


Table 2 Mutations in invasive micropapillary carcinomas (Continued)

\begin{tabular}{|c|c|c|c|c|c|c|c|c|c|c|c|}
\hline SYNRG & 1 & (2) & 17 & ATG $>$ ATA/pM970I & $x$ & $*$ & $x$ & Missense & Transition & 0.45 & Yes \\
\hline UBR4 & 1 & (2) & 1 & AAC $>$ AAA/p.N3400K & $x$ & $x$ & $x$ & Missense & Transversion & 0.98 & Yes \\
\hline ZFYVE26 & 1 & (2) & 14 & CAA $>$ CCA/p.Q1582P & $x$ & $x$ & $x$ & Missense & Transversion & 0.00 & Yes \\
\hline
\end{tabular}

a\%, Percentage of mutated cases out of the sequenced cases; *Assessed but not identified with the technique; Chr, Chromosome; GERP, Genomic Evolutionary Rate Profiling; IMPC, Invasive micropapillary carcinoma; NA, Not assessed with this technique; ND, Not determined (that is, no RNA sequence available for that sample); No coverage, Absence of aligned reads at the corresponding genomic position; WH seq, Whole-exome sequencing; $X$, Assessed and identified with the technique; Yes, Mutated allele is expressed. 


\section{Invasive micropapillary carcinoma DNA and RNA sequencing analysis}

We conducted whole-exome sequencing analyses of four IMPC cases (one "Sawtooth/8/16" and three "Firestorm/ Amplifier"), followed by targeted sequencing analyses (MiSeq) of forty-seven IMPC cases. Twenty-nine tumourspecific, nonsynonymous variants were identified, twentytwo of which were validated by classical Sanger sequencing.

Altogether, 36 nonsynonymous variants were identified by classical Sanger, whole-exome and targeted (MiSeq) sequencing. These nonsynonymous variants were located in 23 different genes and observed in 14 of the 47 IMPC samples (30\%). One-third of the mutated samples harboured more than one nonsynonymous variant. These nonsynonymous variants corresponded to missense mutations in $89 \%$ (32 of 36) of cases and transition in 22 of 36 cases (61\%). They were considered deleterious according to PolyPhen-2 score (higher than 0.5) and GERP score (higher than 4) in 26 (72\%) of 36 cases (Table 2).

RNA sequencing identified seven putative fusion genes. Six of them were further validated (Figure 4): REREACTNA4 t (1;19)(p36.23;q13.2), HEATR7-RSPRY1 t $(8 ; 16)$ (q24.3;q13), ZNF8-GIP t(19;17)(q13.43;q21.32), ZNF256SKA2 t(19;17)(q13.43;q22), DUS1L-B4GALNT2 t(17;17) (q25.3;q21.32) and CHD6-GATA5 t(20;20)(q12;q13.33). All but one of the fusions were private events and observed in one of the thirty-three cases analysed. The ZNF8-GIP fusion was observed in two of thirty-three cases. In addition, two IMPC samples demonstrated several fusion genes (two and three fusion genes per sample). These cases were also associated with point mutations.

\section{Invasive micropapillary carcinomas harboured mutations} in genes involved in polarity, ciliogenesis and cell shape The three most frequently mutated genes in our series of IMPCs were TP53 (10\%), DNAH9 (8\%) and PIK3CA (4\%) (Figure 3A). Among the cases with only TP53 mutations, two also had mutations in genes involved in ciliogenesis (DNAH9, BBS12 and BBS9) or in cytoskeleton organisation (UBR4 and PTPN21). Among the eight cases without TP53 or PIK3CA mutations, three demonstrated multiple mutations (two to six mutations per case). These multiple mutations are located in genes coding for proteins that play a key role in cell polarity (FMN2 and SEC63 (one case (2\%) each) or in biological processes necessary for cell polarity or cell shape, such as ciliogenesis (DNAH9 (two cases (4\%), or cytoskeleton (ZFYVE26 (one case (2\%)). Interactions between the 23 mutated genes and existing signalling pathways were investigated with the Reactome algorithm and are shown in Figure 3B. Fifteen (68\%) of twenty-two of the
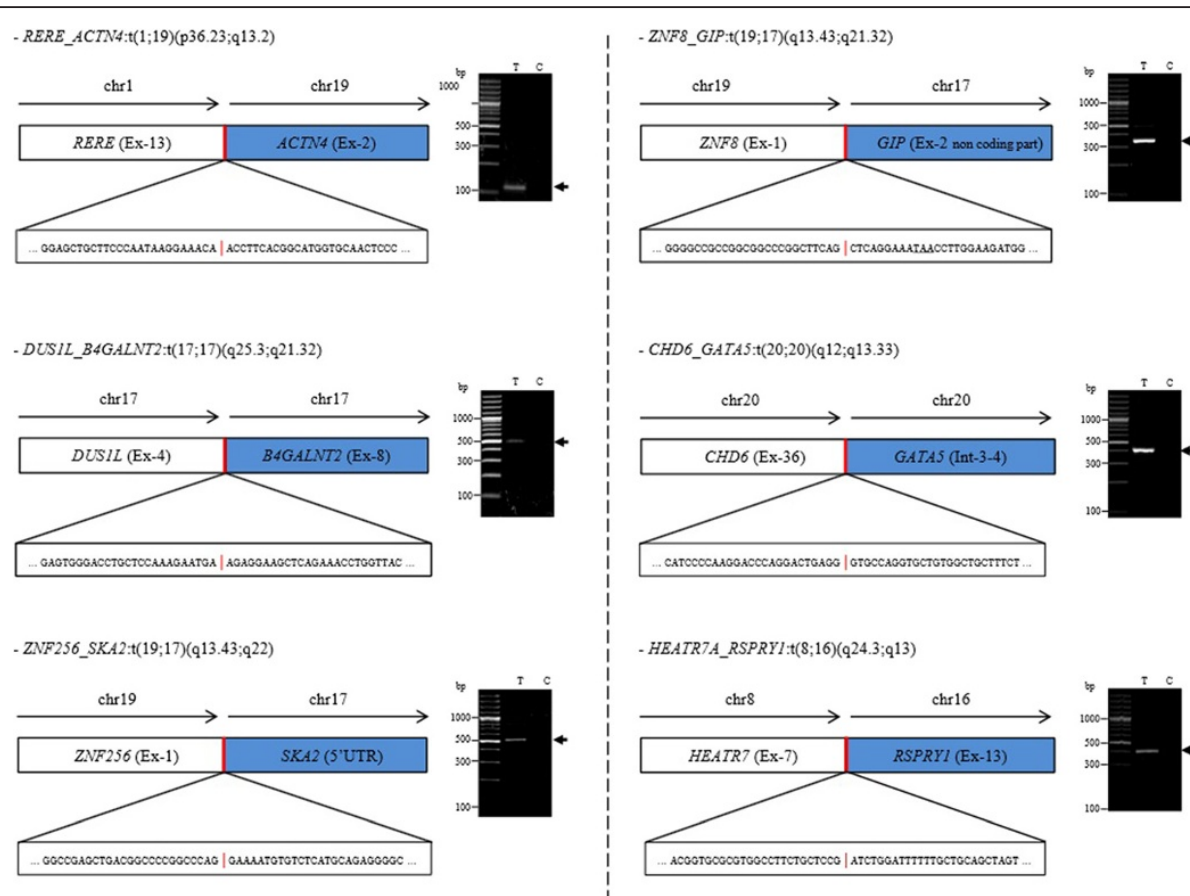

-CHD6_GATAS:t(20;20)(q12;q13.33)

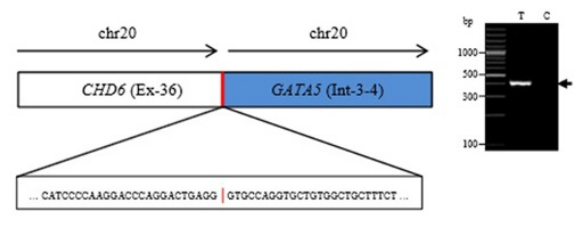

HEATR7A_RSPRYI:t( $(8 ; 16)(q 24.3 ; q 13)$

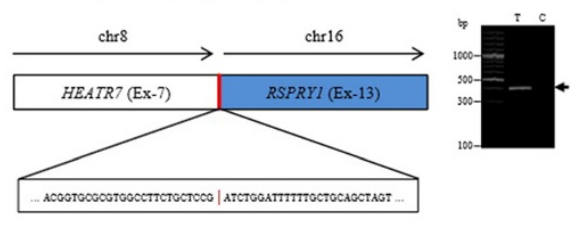

Figure 4 RNA sequencing identification and validation of the six fusions found in invasive micropapillary carcinoma. Schematic representations of the fusions between gene 1 and gene 2 are displayed with the precise sequence of the breakpoint region. In the ZNF8_GIP fusion scheme, the underlined codon is a stop codon. RT-PCR detection of fusion genes in tumour (T) and constitutional (C) RNAs are shown on the right panel for each fusion. The numbers of split and spanning reads, together with the genomic strands of the fused genes, are given in Additional file 3 : Table S8. Primer sequences used for RT-PCR validation are provided in Additional file 4: Table S9. chr, Chromosome; UTR, Untranslated region. 
validated mutations were found to be expressed at the RNA level, which was strongly correlated with Affymetrix Genome-Wide Human SNP 6.0 Array gene expression levels $(R=0.86)$ found in the RNA sequencing data.

\section{Discussion}

In this study, we show that IMPC (1) were luminal and predominantly pT1N1 with high rates of ERBB2 overexpression, (2) were associated with 17q gain/amplification and $6 q$ deletion, (3) encompassed two different genomic subsets (Firestorm/Amplifier or Sawtooth/8/16), (4) harboured SEC63 and FOXO3 gene downregulation and mutation (2\% of cases each) and (5) were localised in the 6q minimal region of deletion. We also describe the genomic landscape of pure micropapillary carcinomas by using tools that enabled us to gain insight into the mutations in genes participating in polarity, ciliogenesis, cell shape and cytoskeleton organisation and private translocation at high resolution.

IMPCs presented with complex genomic profiles and numerous gains, losses or high-level amplifications as well as numerous breakpoints, and, in line with their luminal phenotype, demonstrated a genomic profile that shared similarities with that of ER+N+LVI+ IDC-NSTs with regard to $8 \mathrm{q}$ gains and $8 \mathrm{p}, 16 \mathrm{q}$ and $22 \mathrm{q}$ losses. Some of these alterations have previously been reported to be preferentially associated with luminal B group carcinomas, such as $8 \mathrm{q}$ gains, $8 p$ and $16 q$ losses $[14,36,39]$. However, the high resolution of the present analysis allowed us to identify differences between the two groups, in particular chromosome 17q22-q24.3 gains and 6q16.3-q22.31 losses in IMPCs.

In the present study, we show not only that these $6 \mathrm{q}$ losses exist, confirming a previous report of chromosome 6q losses by Marchio et al. [13], but also show that they were associated with allelic losses in this region. We also found a correlation between genomic status and transcriptomic expression level of the genes located within this 6q region. Two of these genes, SEC63 and FOXO3, were downregulated. We identified a missense mutation in SEC63 and three mutations at different positions in FOXO3 (Table 2). Both the SEC63 and FOXO3 proteins have recently been identified as participating in cell polarity control. SEC63 encodes for an endoplasmic reticulum protein involved in the early stage of multispanning membrane protein synthesis [40] and has been found to be mutated in polycystic liver and kidney diseases [41]. SEC63 protein also participates in quality control and trafficking of proteins necessary for ciliogenesis, and therefore for epithelial cell polarity [42]. FOXO3 is known to regulate $L K B 1$ gene transcription, and the LKB1 protein plays a key role in cell planar polarity during cell division [43]. FOXO3 downregulation has also recently been reported in high-grade serous ovarian carcinoma [44].
The IMPCs we studied had amplification rates of $20 \%$, considered to be high for such early tumours (stage T1). One of the most frequently recurrent regions of amplification observed in IMPCs was located on chromosome 17q22-q23.3. Notably, this region is the hallmark of the cluster 1 of tumours of the METABRIC classification $[7,45]$ and encompasses druggable genes belonging to the kinase family, such as TLK2 and the phosphatase $P P M 1 D$. A the second frequently amplified recurrent region was the $E R B B 2$ region, which was amplified in $22 \%$ of cases, a higher rate than that observed in other $\mathrm{T} 1$ and small T2 IDCs [46,47].

Two of the most frequent regions of amplification in the IDC-NST control group were located on chromosome $8 \mathrm{p}$ and on 11q13.3, which that encompass the FGFR1 and PPAPDC1B genes [48] and the CCND1 gene, respectively. The combination of the CCND1 11q and $8 \mathrm{p}$ regions of amplification has previously been reported to be a characteristic of luminal carcinomas $[49,50]$. The low frequency of amplification of these regions in IMPCs is another genomic difference between luminal IDCNSTs and IMPCs.

Not surprisingly, TP53 and PIK3CA were among the three most recurrent mutated genes in this series of IMPCs. Although TP53 mutation rates were similar to those reported in ER-positive breast carcinomas [7], it is noteworthy that PIK3CA mutations were observed less frequently in IMPCs than in other ER+ histological subgroups [14,51]. Notably, the number of PIK3CA mutations observed in our series of pure IMPCs is much lower than a rate reported recently (four of twenty pure and mixed invasive micropapillary carcinomas) [52].

$D N A H$ gene family mutations were recently identified in triple-negative breast carcinomas, albeit at a very low frequency (3\%) [53]. In our present study of a special type of breast cancer, we identified recurrent mutations of the DNAH9 gene ( $8 \%$ of the cases) by whole-exome sequencing analysis, a rate higher than that reported for luminal IDCs in the TCGA analyses (3\%). Dynein proteins are necessary for correct apical and apicobasal localisation of the CRUMBS [54] and PAR3 [55] proteins. Recurrent DNAH9 mutations in IMPC, characterised by a polarity defect, may suggest a causative role of these mutations in the IMPC pattern of growth that remains to be demonstrated in vitro.

$F M N 2$, a formin-like 2 gene, and the BBS9 and BBS12 genes also harboured mutations, although they were not recurrent. These genes are involved in cell polarity, organisation and motility [56] or ciliogenesis [57]. We noted that the $B B S 9$ and $B B S 12$ genes were not found to be mutated in the TCGA luminal series. Interestingly, in our particular series, these mutations are always associated with multiple other mutations (from four to five) and located in genes coding for proteins that play a role 
in cytoskeleton organisation (HSP90B1, ZFYVE26, UBR4 and PTPN21).

These genes have also been identified to be mutated in triple-negative breast carcinomas [4], which raises the hypothesis of their role in tumour cell invasion and motility enhancement in triple-negative tumours or IMPCs. All of these observations have to be confirmed with the sequence of a larger number of IMPC cases at a higher depth. The clinical impact of our results is not yet straightforward. However, better knowledge of polarity disorganisation in breast carcinomas and its role in tumour progression could lead to new therapeutic strategies if confirmed in a larger series. In agreement with the findings of Natrajan et al. [14], we observed that IMPCs are not associated with recurrent fusion genes.

\section{Conclusion}

In our comprehensive genomic analysis of IMPCs of the breast, we identified numerous genomic alterations and somatic mutations, but no recurrent fusion gene. We demonstrate that IMPC is associated with a specific genomic profile compared to ER+LVI+N+ IDC-NSTs, consisting of gains of 17q, high rates of $17 \mathrm{q} 22-23.3$ and $17 \mathrm{q} 12$ $E R B B 2$ amplifications and losses of $6 \mathrm{q}$ heterozygosity. The presence of the SEC63 and FOXO3 genes located in this $6 \mathrm{q}$ loss of heterozygosity associated with deleterious somatic mutations suggests that they could play a role in the abnormal polarity of IMPC cells. Considered together, the mutation spectrum observed in IMPCs shows that, in addition to TP53 and PIK3CA mutations, some IMPCs harboured mutations in particular in genes involved in ciliogenesis, polarity maintenance and cell shape (often several such mutations per case). However, not all the cases harboured mutations in these biological processes, suggesting that other biological alterations (for example, epigenetic modifications, stromal alterations) could contribute to the morphologically specific pattern of IMPCs, knowing that this hypothesis should be further supported by in vitro experiments.

\section{Additional files}

Additional file 1: Figure S1. Study flow-chart.

Additional file 2: Table S6. Primers used for sequencing SEC63 and FOXO3 genes.

Additional file 3: Two tables. Table S8A: deFuse post analysis filtering. Table S8B: Fusion candidates that were common in TopHat-Fusion and deFuse analysis and had been validated by RT-PCR technique.

Additional file 4: Table S9. RT-PCR primer sequences for fusion validation. Additional file 5: Table S1. Clinical and pathological characteristics. Additional file 6: Figure S2. Intrinsic subtype classification. Intrinsic subtype classification was performed using the PAM50 predictor [35] for all invasive micropapillary carcinoma (IMPC) with available transcriptomic analysis. Samples are displayed in columns, and genes are shown in lines. Above the heatmap, the ERBB2 status (in red: overexpression; in white: no overexpression) and the genomic IMPC subgroups (in yellow: Firestorm/Amplifier; in green: Sawtooth/8/16) are indicated. The IMPCs were distributed either in the luminal B group (16 (47\%) of 34$)$ or in the luminal A group (18 (53\%) 34).

Additional file 7: Table S2. Frequencies of common and specific gains and losses in Sawtooth/8/16 and Firestorm/Amplifier invasive micropapillary carcinoma subsets.

Additional file 8: Table S3. Frequencies of common and specific regions of gains and losses in Firestorm/Amplifier invasive micropapillary carcinoma subgroup and invasive ductal carcinoma of no special type.

Additional file 9: Table S4. Frequencies of common and specific regions of gains and losses in Sawtooth/8/16 invasive micropapillary carcinoma subgroup and invasive ductal carcinoma of no special type.

Additional file 10: Table S5. Comparison of frequency plots of invasive micropapillary carcinoma and luminal B invasive ductal carcinoma of no special type. Frequency plots of gains and losses are displayed from chromosome 1pter on the left to chromosome Xq on the right. Alternating grey and white bands indicate chromosome boundaries. Dashed blue line represent $40 \%$ frequencies, - for losses and + for gains, respectively. IMPC, Invasive micropapillary carcinomas; Luminal B IDC-NST, Luminal B invasive ductal carcinoma of no special type.

Additional file 11: Table S7. Frequencies of common and specific regions of gains and losses in invasive micropapillary carcinoma and luminal B invasive ductal carcinoma of no special type.

Additional file 12: Figure S3. Clinical, pathological characteristics, and treatments of patients and tumours in the two genomic subgroups of invasive micropapillary carcinoma.

\section{Abbreviations}

dbSNP: National Center for Biotechnology Information database of singlenucleotide polymorphism; EMA: Epithelial membrane antigen; ER: Oestrogen receptor; IDC: Invasive ductal carcinoma; IDC-NST: Invasive ductal carcinoma of no special type; IMPC: Invasive micropapillary carcinoma; LVI: Lymphovascular invasion; METABRIC: Molecular Taxonomy of Breast Cancer International Consortium; N+: Lymph node metastasis.; PR: Progesterone receptor; SNP: Single-nucleotide polymorphism; SNV: Single-nucleotide variant; TBP: Tata-binding protein.

\section{Competing interests}

The authors declare that they have no competing interests.

\section{Authors' contributions}

NG performed the experiments, interpreted the data and wrote the manuscript. $J B$ performed the bioinformatics analyses, interpreted the data and contributed to the critical revision of the manuscript. VB, TP and MHS performed the SNP6.0 data GAP analysis and contributed to the critical revision of the manuscript. VB and VR performed part of the experiments and contributed to the critical revision of the manuscript. OM prepared the nucleic acids and contributed to the critical revision of the manuscript. PF and LA provided IMPC samples and contributed to the critical revision of the manuscript. RR and XSG participated in the study design and collection of the clinical data and contributed to the critical revision of the manuscript. OD and AVS designed the study, interpreted the data and wrote the manuscript. All authors read and approved the final manuscript.

\section{Acknowledgements}

The authors would like to thank David Gentien, Cécile Reyes, Jean Philippe Meyniel, Guillem Riguaill and Sergio Roman-Roman for their help provided to Vanessa Benhamo with the SNP6.0 experiments at the Institut Curie Translational Research Department. We also thank Dr Anthony Saul for the English editing. AVS is supported by an INTERFACE grant from INSERM. Financial support for the experiments was provided by the Institut Curie Translational Department, the "Association pour la Recherche contre le Cancer" (ARC) AAP 2010 (SFI20101201734) and the Institut Curie "ICGEX" grant for whole-exome sequencing experiments. JB is supported by French National Institute of Cancer grant "GEPIG." Support was also provided via the Pink Ribbon Award 2012 (Estée Lauder and "Le cancer du sein, Parlons-en!" charity organisation), given in 2012 to AVS. 


\section{Author details}

'INSERM U830, Institut Curie, 26 rue d'Ulm, 75248 Paris Cédex 05, France. ${ }^{2}$ Department of Translational Research, Institut Curie, 26 rue d'Ulm, 75248 Paris Cédex 05, France. ${ }^{3}$ Department of Tumor Biology, Institut Curie, 26 rue d'Ulm, 75248 Paris Cédex 05, France. ${ }^{4}$ Department of Pathology, Centre Georges François Leclerc, and CRB Ferdinand Cabanne, 1 rue Professeur Marion BP 77 980, 21079 Dijon Cédex, France. ${ }^{5}$ Department of Surgery, Institut Curie, 26 rue d'Ulm, 75248 Paris Cédex 05, France.

\section{Received: 13 March 2013 Accepted: 1 April 2014}

\section{Published: 8 May 2014}

\section{References}

1. Lakhani SR, Ellis IO, Schnitt SJ, Tan PH, van de Vijver MJ (E): WHO Classification of Tumours of the Breast, (WHO Classification of Tumours, Volume 4). Lyon, France: International Agency for Research on Cancer; 2012.

2. Weigelt B, Geyer FC, Reis-Filho JS: Histological types of breast cancer: how special are they? Mol Oncol 2010, 4:192-208.

3. Weigelt B, Horlings HM, Kreike B, Hayes MM, Hauptmann M, Wessels LF, de Jong $D$, van de Vijver MJ, van 't Veer LJ, Peterse JL: Refinement of breast cancer classification by molecular characterization of histological special types. J Pathol 2008, 216:141-150.

4. Banerji S, Cibulskis K, Rangel-Escareno C, Brown KK, Carter SL, Frederick AM, Lawrence MS, Sivachenko AY, Sougnez C, Zou L, Cortes ML, FernandezLopez JC, Peng S, Ardlie KG, Auclair D, Bautista-Piña V, Duke F, Francis J, Jung J, Maffuz-Aziz A, Onofrio RC, Parkin M, Pho NH, Quintanar-Jurado V, Ramos AH, Rebollar-Vega R, Rodriguez-Cuevas S, Romero-Cordoba SL, Schumacher SE, Stransky N, et al: Sequence analysis of mutations and translocations across breast cancer subtypes. Nature 2012, 486:405-409.

5. Cancer Genome Atlas Network: Comprehensive molecular portraits of human breast tumours. Nature 2012, 490:61-70.

6. Shah SP, Morin RD, Khattra J, Prentice L, Pugh T, Burleigh A, Delaney A, Gelmon K, Guliany R, Senz J, Steidl C, Holt RA, Jones S, Sun M, Leung G, Moore R, Severson T, Taylor GA, Teschendorff AE, Tse K, Turashvili G, Varho R, Warren RL, Watson P, Zhao Y, Caldas C, Huntsman D, Hirst M, Marra MA, Aparicio S: Mutational evolution in a lobular breast tumour profiled at single nucleotide resolution. Nature 2009, 461:809-813.

7. Curtis C, Shah SP, Chin SF, Turashvili G, Rueda OM, Dunning MJ, Speed D, Lynch AG, Samarajiwa S, Yuan Y, Gräf S, Ha G, Haffari G, Bashashati A, Russell R, McKinney S, METABRIC Group, Langerød A, Green A, Provenzano E, Wishart G, Pinder S, Watson P, Markowetz F, Murphy L, Ellis I, Purushotham A, Børresen-Dale AL, Brenton JD, Tavaré $S$, et al: The genomic and transcriptomic architecture of 2,000 breast tumours reveals novel subgroups. Nature 2012, 486:346-352.

8. Nassar H, Wallis T, Andea A, Dey J, Adsay V, Visscher D: Clinicopathologic analysis of invasive micropapillary differentiation in breast carcinoma. Mod Pathol 2001, 14:836-841.

9. Paterakos M, Watkin WG, Edgerton SM, Moore DH 2nd, Thor AD: Invasive micropapillary carcinoma of the breast: a prognostic study. Hum Pathol 1999, 30:1459-1463.

10. Chen L, Fan Y, Lang RG, Guo XJ, Sun YL, Cui LF, Liu FF, Wei J, Zhang XM, Fu $L$ : Breast carcinoma with micropapillary features: clinicopathologic study and long-term follow-up of 100 cases. Int I Surg Pathol 2008, 16:155-163.

11. van der Vegt $B$, de Roos MA, Peterse JL, Patriarca C, Hilkens J, de Bock GH, Wesseling J: The expression pattern of MUC1 (EMA) is related to tumour characteristics and clinical outcome of invasive ductal breast carcinoma. Histopathology 2007, 51:322-335.

12. Thor AD, Eng C, Devries S, Paterakos M, Watkin WG, Edgerton S, Moore DH 2nd, Etzell J, Waldman FM: Invasive micropapillary carcinoma of the breast is associated with chromosome 8 abnormalities detected by comparative genomic hybridization. Hum Pathol 2002, 33:628-631.

13. Marchiò C, Iravani M, Natrajan R, Lambros MB, Savage K, Tamber N, Fenwick K, Mackay A, Senetta R, Di Palma S, Schmitt FC, Bussolati G, Ellis LO, Ashworth A, Sapino A, Reis-Filho JS: Genomic and immunophenotypical characterization of pure micropapillary carcinomas of the breast. J Pathol 2008, 215:398-410

14. Natrajan R, Wilkerson PM, Marchio C, Piscuoglio S, Ng CK, Wai P, Lambros MB, Samartzis EP, Dedes KJ, Frankum J, Bajrami I, Kopec A, Mackay A, A'hern R, Fenwick K, Kozarewa I, Hakas J, Mitsopoulos C, Hardisson D, Lord CJ, Kumar-Sinha C, Ashworth A, Weigelt B, Sapino A, Chinnaiyan AM, Maher CA, Reis-Filho JS: Characterization of the genomic features and expressed fusion genes in micropapillary carcinomas of the breast. J Pathol 2014 232:553-565.

15. Nassar $H$, Pansare V, Zhang H, Che M, Sakr W, Ali-Fehmi R, Grignon D, Sarkar F, Cheng J, Adsay V: Pathogenesis of invasive micropapillary carcinoma: role of MUC1 glycoprotein. Mod Pathol 2004, 17:1045-1050.

16. Wolff AC, Hammond ME, Schwartz JN, Hagerty KL, Allred DC, Cote RJ, Dowsett M, Fitzgibbons PL, Hanna WM, Langer A, McShane LM, Paik S, Pegram MD, Perez EA, Press MF, Rhodes A, Sturgeon C, Taube SE, Tubbs R, Vance GH, van de Vijver M, Wheeler TM, Hayes DF, American Society of Clinical Oncology/College of American Pathologists: American Society of Clinical Oncology/College of American Pathologists guideline recommendations for human epidermal growth factor receptor 2 testing in breast cancer. Arch Pathol Lab Med 2007, 131:18.

17. Hammond ME, Hayes DF, Wolff AC, Mangu PB, Temin S: American Society of Clinical Oncology/College of American Pathologists guideline recommendations for immunohistochemical testing of estrogen and progesterone receptors in breast cancer. J Oncol Pract 2010, 6:195-197.

18. Gruel N, Lucchesi C, Raynal V, Rodrigues MJ, Pierron G, Goudefroye R, Cottu P, Reyal F, Sastre-Garau X, Fourquet A, Delattre O, Vincent-Salomon A: Lobular invasive carcinoma of the breast is a molecular entity distinct from luminal invasive ductal carcinoma. Eur J Cancer 2010, 46:2399-2407.

19. Gruel N, Benhamo V, Popova T, Cedenot A, Mariani O, Gautier A, Cascone I, Arnould L, Fréneaux P, Bhalshankar J, Assayag F, Pierron G, Reyal F, Alran S, Cottu P, Fourquet A, Sastre-Garau X, Stern M, Camonis J, Delattre O, Vincent-Salomon A: Polarity gene alterations in pure invasive micropapillary carcinomas of the breast. Gene Expression Omnibus (GEO) accession no. [GEO: GSE37035]. http://www.ncbi.nlm.nih.gov/geo/query/acc.cgi?acc=GSE37035 [accessed 15 May 2014].

20. Popova T, Manié E, Stoppa-Lyonnet D, Rigaill G, Barillot E, Stern MH: Genome Alteration Print (GAP): a tool to visualize and mine complex cancer genomic profiles obtained by SNP arrays. Genome Biol 2009, 10:R128.

21. Nielsen TO, Parker JS, Leung S, Voduc D, Ebbert M, Vickery T, Davies SR, Snider J, Stijleman IJ, Reed J, Cheang MC, Mardis ER, Perou CM, Bernard PS, Ellis MJ: A comparison of PAM50 intrinsic subtyping with immunohistochemistry and clinical prognostic factors in tamoxifen-treated estrogen receptor-positive breast cancer. Clin Cancer Res 2010, 16:5222-5232.

22. National Institutes of Health, National Cancer Institute: The Cancer Genome Atlas (TCGA) Data Portal: Understanding Genomics to Improve Cancer Care. Available at https:/tcga-data.nci.nih.gov/tcga/ [accessed 15 May 2014].

23. Adzhubei IA, Schmidt S, Peshkin L, Ramensky VE, Gerasimova A, Bork P, Kondrashov AS, Sunyaev SR: A method and server for predicting damaging missense mutations. Nat Methods 2010, 7:248-249. http://genetics.bwh.harvard.edu/pph2/.

24. Homer N, Merriman B, Nelson SF: BFAST: an alignment tool for large scale genome resequencing. PLOS One 2009, 4:e7767.

25. Li H, Handsaker B, Wysoker A, Fennell T, Ruan J, Homer N, Marth G, Abecasis G, Durbin R, 1000 Genome Project Data Processing Subgroup: The Sequence Alignment/Map format and SAMtools. Bioinformatics 2009, 25:2078-2079.

26. Koboldt DC, Zhang Q, Larson DE, Shen D, McLellan MD, Lin L, Miller CA, Mardis ER, Ding L, Wilson RK: VarScan 2: somatic mutation and copy number alteration discovery in cancer by exome sequencing. Genome Res 2012, 22:568-576.

27. Ng SB, Turner EH, Robertson PD, Flygare SD, Bigham AW, Lee C, Shaffer T, Wong M, Bhattacharjee A, Eichler EE, Bamshad M, Nickerson DA, Shendure J: Targeted capture and massively parallel sequencing of 12 human exomes. Nature 2009, 46:272-276.

28. Reactome Wiki: A Curated Pathway Database. Available at http://wiki.reactome. org/index.php/Reactome_Fl_Cytoscape_Plugin [accessed 15 May 2014].

29. Davydov EV, Goode DL, Sirota M, Cooper GM, Sidow A, Batzoglou S: Identifying a high fraction of the human genome to be under selective constraint using GERP++. PLoS Comput Biol 2010, 6:e1001025.

30. McKusick-Nathans Institute of Genetic Medicine, University of Maryland Center for Bioinformatics and Computational Biology: TopHat: A Spliced Read Mapper for RNA-Seq. Available at http://tophat.cbcb.umd.edu/ [accessed 15 May 2014].

31. University of Maryland Center for Bioinformatics and Computational Biology: Cufflinks: Transcript Assembly, Differential Expression, and Differential Regulation for RNA-Seq. Available at http://cufflinks.cbcb.umd.edu/ [accessed 15 May 2014].

32. Kim D, Salzberg SL: TopHat-Fusion: an algorithm for discovery of novel fusion transcripts. Genome Biol 2011, 12:R72 
33. McPherson A, Hormozdiari F, Zayed A, Giuliany R, Ha G, Sun MG, Griffith M, Heravi Moussavi A, Senz J, Melnyk N, Pacheco M, Marra MA, Hirst M, Nielsen TO, Sahinalp SC, Huntsman D, Shah SP: deFuse: an algorithm for gene fusion discovery in tumor RNA-Seq data. PLoS Comput Biol 2011, 7:e1001138.

34. Trapnell C, Pachter L, Salzberg SL: TopHat: discovering splice junctions with RNA-Seq. Bioinformatics 2009, 25:1105-1111.

35. Parker JS, Mullins M, Cheang MC, Leung S, Voduc D, Vickery T, Davies S, Fauron C, He X, Hu Z, Quackenbush JF, Stijleman IJ, Palazzo J, Marron JS, Nobel AB, Mardis E, Nielsen TO, Ellis MJ, Perou CM, Bernard PS: Supervised risk predictor of breast cancer based on intrinsic subtypes. J Clin Oncol 2009, 27:1160-1167.

36. Chin K, DeVries S, Fridlyand J, Spellman PT, Roydasgupta R, Kuo WL, Lapuk A, Neve RM, Qian Z, Ryder T, Chen F, Feiler H, Tokuyasu T, Kingsley C, Dairkee S, Meng Z, Chew K, Pinkel D, Jain A, Ljung BM, Esserman L, Albertson DG, Waldman FM, Gray JW: Genomic and transcriptional aberrations linked to breast cancer pathophysiologies. Cancer Cell 2006, 10:529-541.

37. Marchiò C, Natrajan R, Shiu KK, Lambros MB, Rodriguez-Pinilla SM, Tan DS, Lord CJ, Hungermann D, Fenwick K, Tamber N, Mackay A, Palacios J, Sapino A, Buerger H, Ashworth A, Reis-Filho JS: The genomic profile of HER2amplified breast cancers: the influence of ER status. J Pathol 2008, 216:399-407.

38. Matthews L, Gopinath G, Gillespie M, Caudy M, Croft D, de Bono B, Garapati $P$ Hemish J, Hermjakob H, Jassal B, Kanapin A, Lewis S, Mahajan S, May B, Schmidt E, Vastrik I, Wu G, Birney E, Stein L, D'Eustachio P: Reactome knowledgebase of human biological pathways and processes. Nucleic Acids Res 2009, 37:D619-D622.

39. Jonsson G, Staaf J, Vallon-Christersson J, Ringner M, Holm K, Hegardt C, Gunnarsson H, Fagerholm R, Strand C, Agnarsson BA, Kilpivaara O, Luts L, Heikkilä P, Aittomäki K, Blomqvist C, Loman N, Malmström P, Olsson H, Johannsson OT, Arason A, Nevanlinna H, Barkardottir RB, Borg A: Genomic subtypes of breast cancer identified by array-comparative genomic hybridization display distinct molecular and clinical characteristics. Breast Cancer Res 2010, 12:R42.

40. Stephens PJ, Tarpey PS, Davies H, Van Loo P, Greenman C, Wedge DC, Nik-Zainal S, Martin S, Varela I, Bignell GR, Yates LR, Papaemmanuil E, Beare D, Butler A, Cheverton A, Gamble J, Hinton J, Jia M, Jayakumar A, Jones D, Latimer C, Lau KW, McLaren S, McBride DJ, Menzies A, Mudie L, Raine K, Rad R, Chapman MS, Teague J, et al: The landscape of cancer genes and mutational processes in breast cancer. Nature 2012, 486:400-404.

41. Banales JM, Munoz-Garrido P, Bujanda L: Somatic second-hit mutations leads to polycystic liver diseases. World J Gastroenterol 2013, 19:141-143.

42. Bergmann C, Weiskirchen R: It's not all in the cilium, but on the road to it: genetic interaction network in polycystic kidney and liver diseases and how trafficking and quality control matter. J Hepatol 2011, 56:1201-1203.

43. Lützner N, Kalbacher H, Krones-Herzig A, Rösl F: FOXO3 is a glucocorticoid receptor target and regulates LKB1 and its own expression based on cellular AMP levels via a positive autoregulatory loop. PLoS One 2012, 7:e42166.

44. McMillen BD, Aponte MM, Liu Z, Helenowski IB, Scholtens DM, Buttin BM, Wei JJ: Expression analysis of MIR182 and its associated target genes in advanced ovarian carcinoma. Mod Pathol 2012, 25:1644-1653.

45. Dawson SJ, Rueda OM, Aparicio S, Caldas C: A new genome-driven integrated classification of breast cancer and its implications. EMBO J 2013, 32:617-628.

46. Rodrigues MJ, Wassermann J, Albiges L, Brain E, Delaloge S, Stevens D, Guinebretière JM, Mathieu MC, Kirova Y, Guillot E, Vincent-Salomon A, Cottu $\mathrm{PH}$ : Trastuzumab treatment in T1ab, node-negative, human epidermal growth factor receptor 2-overexpressing breast carcinomas. J Clin Oncol 2010, 28:e541-e542

47. Curigliano G, Viale G, Bagnardi V, Fumagalli L, Locatelli M, Rotmensz N, Ghisini R, Colleoni M, Munzone E, Veronesi P, Zurrida S, Nolè F, Goldhirsch A: Clinical relevance of HER2 overexpression/amplification in patients with small tumor size and node-negative breast cancer. J Clin Oncol 2009, 27:5693-5699.

48. Bernard-Pierrot I, Gruel N, Stransky N, Vincent-Salomon A, Reyal F, Raynal V Vallot C, Pierron G, Radvanyi F, Delattre O: Characterization of the recurrent 8p11-12 amplicon identifies PPAPDC1B, a phosphatase protein, as a new therapeutic target in breast cancer. Cancer Res 2008, 68:7165-7175.
49. Kwek SS, Roy R, Zhou H, Climent J, Martinez-Climent JA, Fridlyand J, Albertson DG: Co-amplified genes at $8 \mathrm{p} 12$ and $11 \mathrm{q} 13$ in breast tumors cooperate with two major pathways in oncogenesis. Oncogene 2009, 28:1892-1903.

50. Adélaïde J, Finetti P, Bekhouche I, Repellini L, Geneix J, Sircoulomb F, Charafe-Jauffret E, Cervera N, Desplans J, Parzy D, Schoenmakers E, Viens P, Jacquemier J, Birnbaum D, Bertucci F, Chaffanet M: Integrated profiling of basal and luminal breast cancers. Cancer Res 2007, 67:11565-11575.

51. Buttitta F, Felicioni L, Barassi F, Martella C, Paolizzi D, Fresu G, Salvatore S, Cuccurullo F, Mezzetti A, Campani D, Marchetti A: PIK3CA mutation and histological type in breast carcinoma: high frequency of mutations in lobular carcinoma. J Pathol 2006, 208:350-355.

52. Flatley E, Ang D, Warrick A, Beadling C, Corless CL, Troxell ML: PIK3CA-AKT pathway mutations in micropapillary breast carcinoma. Hum Pathol 2013, 44:1320-1327

53. Shah SP, Roth A, Goya R, Oloumi A, Ha G, Zhao Y, Turashvili G, Ding J, Tse K, Haffari G, Bashashati A, Prentice LM, Khattra J, Burleigh A, Yap D, Bernard V, McPherson A, Shumansky K, Crisan A, Giuliany R, Heravi-Moussavi A, Rosner J, Lai D, Birol I, Varhol R, Tam A, Dhalla N, Zeng T, Ma K, Chan SK, et al: The clonal and mutational evolution spectrum of primary triple-negative breast cancers. Nature 2012, 486:395-399.

54. Li Z, Wang L, Hays TS, Cai Y: Dynein-mediated apical localization of crumbs transcripts is required for crumbs activity in epithelial polarity. J Cell Biol 2008, 180:31-38.

55. Schmoranzer J, Fawcett JP, Segura M, Tan S, Vallee RB, Pawson T, Gundersen GG: Par3 and dynein associate to regulate local microtubule dynamics and centrosome orientation during migration. Curr Biol 2009, 19:1065-1074.

56. Kitzing TM, Wang Y, Pertz O, Copeland JW, Grosse R: Formin-like 2 drives amoeboid invasive cell motility downstream of RhoC. Oncogene 2010, 29:2441-2448

57. Garcia-Gonzalo FR, Reiter JF: Scoring a backstage pass: mechanisms of ciliogenesis and ciliary access. J Cell Biol 2012, 197:697-709.

doi:10.1186/bcr3653

Cite this article as: Gruel et al:: Polarity gene alterations in pure invasive micropapillary carcinomas of the breast. Breast Cancer Research 2014 16:R46.

\section{Submit your next manuscript to BioMed Central and take full advantage of:}

- Convenient online submission

- Thorough peer review

- No space constraints or color figure charges

- Immediate publication on acceptance

- Inclusion in PubMed, CAS, Scopus and Google Scholar

- Research which is freely available for redistribution 